\title{
Model Pendidikan Multikultural
}

\begin{abstract}
The theology subject taught at the school tends merely to reinforce the faith and its achievements to go to heaven without consciousness for having dialogue with other religions. These conditions make religious education very exclusive and intolerant. The Model of multicultural education as an alternative solution to reduce That exclusive and intolerant. Multicultural education can serve as a transformational process, not merely tolerance process; it is not just teaching about different cultures of various ethnic and religious group and supports the appreciation, comfort, cosmos, tolerance of other cultures.
\end{abstract}

Keywords: Islamic education, Multicultural, Inclusif, Tolerant

\begin{abstract}
Abstrak
Pelajaran teologi di sekolah cenderung diajarkan sekedar untuk memperkuat keimanan dan pencapaiannya menuju surga tanpa dibarengi dengan kesadaran berdialog dengan agama-agama lain. Kondisi inilah yang menjadikan pendidikan agama sangat eksklusif dan tidak toleran. Untuk itu Model Pendidikan multikultural bisa menjadi suatu alternaatifnya. Karena proses transformasional, bukan sekedar proses toleransi. rtinya pendidikan multikultural bukan sekedar mengajar tentang kebudayaan yang berbeda-beda kebudayaan dari berbagai kelompok etnik dan keagamaan dan mendukung apresiasi, kenyamanan, toleransi tehadap budaya lain.
\end{abstract}

Kata Kunci: Pendidikan Agama Islam, Multikultural, Inklusif, Toleran

Junaidi

Dosen PAI STAI Darul Hikmah Bangkalan

Junaidi@darul-hikmah.com 


\section{A. Pendidikan Multikultural}

Secara etimologi istilah pendidikan multikultural terdiri dari dua term, yaitu pendidikan dan multikultural. Pendidikan berarti proses pengembangan sikap dan tata laku seseorang atau kelompok dalam usaha mendewasakan melalui pengajaran, pelatihan, proses dan cara mendidik. ${ }^{1}$ Multikultural diartikan sebagai keragaman kebudayaan, aneka kesopanan. ${ }^{2}$ Sedangkan secara terminologi, pendidikan multikultural berarti proses pengembangan seluruh potensi manusia yang menghargai pluralitas dan heterogenitasnya sebagai konsekuensi keragaman budaya, etnis, suku dan aliran (agama). ${ }^{3}$

Selanjutnya menurut Banks pendidikan multikultural adalah "multicultural education is a concept, a frame work, a way of thinking, a philosophical viewpoint, a value orientation, and a set of educational nedds of culturally diverse student populations". Maksudnya bahwa pendidikan multikultural adalah konsep, ide atau falsafah sebagai suatu rangkaian kepercayaan (set of believe) dan penjelasan yang mengakui dan menilai pentingnya keragaman budaya dan etnis di dalam membentuk gaya hidup, pengalaman sosial, identitas pribadi, kesempatan-kesempatan pendidikan dari individu, kelompok maupun negara. ${ }^{4}$ Oleh karena itu pendidikan multicultural ditujukan untuk mempersiapkan peserta didik dengan sejumlah sikap dan keterampilan yang diperlukan dalam lingkungan budaya etnik mereka, budaya nasional dan antar budaya etnik lainnya. Pendapat yang tidak jauh berbeda juga dikemukakan oleh Skeel, bahwa pendidikan multikultural adalah suatu sikap dalam memandang keunikan manusia dengan tanpa membedakan

\footnotetext{
${ }^{1}$ Bukhari Umar, Ilmu Pendidikan Islam (Jakarta: Amzah, 2010), hlm. 28

${ }^{2}$ Masgnud, Pendidikan Multikultural: Pemikiran dan Upaya Implementasinya, (Yogyakarta: Idea Press, 2010), hlm. 19

${ }^{3}$ Ibid., hlm. 21

${ }^{4}$ Banks, james and Cherry McGee Banks (eds). (2001). Multicultural Education Issues and Perspectives. New York: John Wiley and Sons.
} 


\section{Model Pendidikan Multikultural}

ras, budaya, jenis kelamin, seks, kondisi jasmaniah atau status ekonomi seseorang. 5

Pendapat lain sebagaimana yang diungkapkan oleh Ainul Yaqin bahwa pendidikan multicultural adalah strategi pendidikan yang diaplikasikan pada semua jenis mata pelajaran dengan cara menggunakan perbedaan-perbedaan cultural yang ada pada peserta didik, seperti perbedaan etnis, agama, bahasa, gender, kelas social, ras, kemampuan dan umur agar proses belajar menjadi efektif dan mudah. ${ }^{6}$ Lebih lanjut Ainul mengungkapkan bahwa pendidikan multicultural juga untuk melatih dan membangun karakter siswa agar mampu bersikap demokratis, humanis dan pluralis dalam lingkungan mereka. ${ }^{7}$ Mengenai fokus pendidikan multikultural, Tilaar mengungkapkan bahwa dalam program pendidikan multikultural, fokus tidak lagi diarahkan semata-mata kepada kelompok rasial, agama dan kultural domain atau mainstream. Fokus seperti ini pernah menjadi tekanan pada pendidikan interkultural yang menekankan peningkatan pemahaman dan toleransi individu-individu yang berasal dari kelompok minoritas terhadap budaya mainstream yang dominan, yang pada akhirnya menyebabkan orang-orang dari kelompok minoritas terintegrasi ke dalam masyarakat mainstream. Pendidikan multikultural sebenarnya merupakan sikap "peduli" dan mau mengerti (difference), atau "politics of recognition" politik pengakuan terhadap orang-orang dari kelompok minoritas. ${ }^{8}$

Melihat dan memperhatikan pengertian pendidikan multikultural di atas, dapat diambil beberapa pemahaman, diantaranya; 1) pendidikan multikultural merupakan sebuah proses pendidikan yang tidak mengenal batasan atau sekat-sekat dalam segi kehidupan manusia; 2) pendidikan

${ }^{5}$ Skeel, Dorothy J. (1995). Elementary social studies : Challenges for tomorrow's world. Harcourt Brace College Publishers.

${ }^{6}$ M. Ainul Yaqin, Pendidikan Multikultural: Cross-Cultural Understanding untuk Demokrasi dan Keadilan(Yogyakarta:Pilar Media, 2005), hlm 25

${ }^{7}$ M. Ainul Yaqin, Pendidikan Multikultural: Cross-Cultural Understanding untuk Demokrasi dan Keadilan(Yogyakarta:Pilar Media, 2005), hlm 25

${ }^{8}$ H.A.R, Tilaar, Perubahan Sosial dan Pendidikan: Pengantar Pedagogik Transformatif untuk Indonesia(Jakarta: Grasindo, 2002), hlm. 59 
multikultural merupakan pengembangan seluruh potensi manusia, baik intelektual, moral, spiritual, maupun tradisi budaya. 3) pendidikan multikultural adalah pendidikan yang menghargai dan menjunjung tinggi keragaman budaya, etnis, suku dan agama.

Adapun tujuan pendidikan yang berbasis multikultural sebagaimana yang diungkapkan oleh Skeel adalah sebagai berikut; 1) untuk memfungsikan peranan sekolah dalam memandang keberadaan siswa yang beraneka ragam; 2) untuk membantu siswa dalam membangun perlakuan yang positif terhadap perbedaan kultural, ras, etnis, kelompok keagamaan; 3) memberikan ketahanan siswa dengan cara mengajar mereka dalam mengambil keputusan dan keterampilan sosialnya; 4) untuk membantu peserta didik dalam membangun ketergantungan lintas budaya dan memberi gambaran positif kepada mereka mengenai perbedaan kelompok. ${ }^{9}$

Dengan demikian, pendidikan mutikultural merupakan proses penanaman cara hidup menghormati, tulus dan toleran terhadap keragaman budaya yang hidup di tengah-tengah masyarakat plural. Baik itu melalui pendidikan formal (sekolah), non formal (luar sekolah) maupun informal (keluarga). Sehingga implementasi pendidikan multikultural di sekolah tidak perlu dalam bentuk mata pelajaran tersendiri, tetapi dapat direalisasikan dalam bentuk pembelajaran multikultural, yaitu dengan diintegrasikan pada berbagai macam Mata Pelajaran yang sudah ada seperti PKN, Bahasa, IPS, Agama termasuk Akidak Akhlak yang akan menjadi kajian utama dalam penelitian ini.

\section{B. Landasan Religius tentang Pendidikan Multiculture}

Secara normatif teologis, Islam telah mengajarkan nilai-nilai pendidikan multikultural; diantaranya nilai keadilan, kesetaraan, keragaman dll. Dasar-dasar tersebut antara lain, terdapat dalam QS. Al-Hujurat ayat

9 Skeel, Dorothy J. (1995). Elementary social studies : Challenges for tomorrow's world. Harcourt Brace College Publishers. 


\section{Model Pendidikan Multikultural}

11-13, al- Mumtahanah ayat 7-9, asy-Syuro ayat 38, al Hadid ayat 25, dan surat al-A'raf ayat 181 .

Ayat-ayat tersebut memberikan landasan moral dan etik kepada kita untuk berprilaku adil. Maksud adil disini adalah berkaitan dengan interaksi sosial, yaitu dalam hubungan sosial sesama manusia (hablu minannas), sehingga adil tidak dapat diartikan hanya pada satu kelompok atau golongan saja tetapi kepada semua manusia di bumi, karena Islam untuk rahmatan lil alamin. Dengan kata lain, Islam tidak mengajarkan doktrin rasisme yang menempatkan sesuatu kelompok secara superior atas kelompok lain karena faktor ras dan etnik. ${ }^{10}$

Untuk mengembangkan nilai-nilai pendidikan multikultural seperti nilai demokratis, kesetaraan, keadilan dalam masyarakat heterogen sebagaimana di Indonesia diperlukan sebuah orientasi hidup universal. Diantaraya kehidupan yang dilandasi nilai kemanusiaan, kebersamaan dan keadian. Orientasi inilah yang dijadikan sebagai pangkal bagi penyelenggara pendidikan. ${ }^{11}$ Dalam Islam nilai kebersamaan yang menjadi titik orientasi penyelenggaraan pendidikan sejalan dengan konsep saling mengenal (taaruf) dan saling tolong menolong (taawun). Kedua konsep tersebut sebagaimana terdapat dalam QS. Al-Hujurat ayat 13 yang berbunyi;

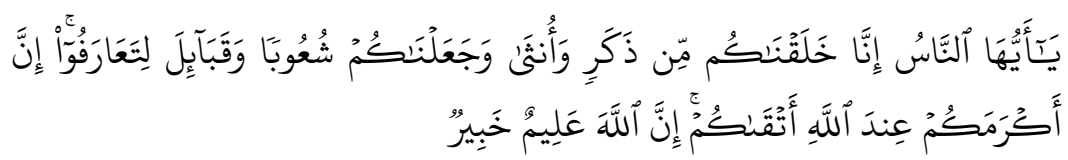

"Hai manusia, Sesungguhnya Kami menciptakan kamu dari seorang laki-laki dan seorang perempuan dan menjadikan kamu berbangsa - bangsa dan bersuku-suku supaya kamu saling kenalmengenal. Sesungguhnya orang yang paling mulia diantara kamu disisi Allah ialah orang yang paling taqwa diantara kamu. Sesungguhnya Allah Maha mengetahui lagi Maha Mengenal."

\footnotetext{
${ }^{10}$ Ibid,.

${ }^{11}$ Nimrod aloni, enciclopedia of humanistic educational. New york: oxford university press, 1999. Hlm. 111
} 
Dalam tafsir Ibnu Katsir ayat ini mengandung makna bahwa "Allah sedang memberitahukan kepada manusia "sesungguhnya Dia telah menciptakan manusia dari tubuh satu orang saja, dan menjadikan dari tubuh tersebut pasanganya, mereka adalah adam dan hawa, dan Allah menjadikan manusia itu menjadi beberapa bangsa dan suku, yaitu sukusuku pada umumnya, setelah bersuku-suku di lanjutkan yang lainnya, seperti beberapa bagian, beberapa kabilah, beberapa tempat tinggal, dan lain sebagainya. ",2

Selanjutnya dikatakan bahwa Allah menciptakan manusia dari seorang laki-laki (Adam) dan seorang perempuan (Hawa), dan menjadikannya berbangsa-bangsa, bersuku-suku, dan berbeda-beda warna kulit bukan untuk saling mencemoohkan, tetapi untuk saling mengenal dan menolong. Allah tidak menyukai orang-orang yang memperlihatkan kesombongan dengan keturunan, kepangkatan atau kekayaan karena yang mulia diantara manusia disisi Allah hanyalah orang yang bertakwa kepadaNya. ${ }^{13}$ Kebiasaan manusia memandang kemuliaan itu ada sangkut pautnya dengan kebangsaan dan kekayaan. Padahal menurut pandangan Allah, orang yang mulia itu adalah orang yang paling bertakwa kepada Allah. Mengapa manusia saling menolok-olok sesama saudara hanya karena Allah menjadikan mereka bersuku-suku dan berkabilah-kabilah yang berbedabeda, sedangkan Allah menjadikan seperti itu agar manusia saling mengenal dan saling tolong menolong dan kemaslahatan-maslahatan mereka yang bermacam-macam. Namun tidak ada kelebihan bagi seseorangpun atas yang lain, kecuali dengan taqwa dan keshalihan, disamping kesempurnaan jiwa bukan dengan hal-hal yang bersifat keduniaan yang tidak pernah abadi.

Diriwayatkan pula dari Abu Malik Al-Asy'ari, ia berkata bahwa Rasulullah bersabda, "sesungguhnya Allah tidak memandang kepada

\footnotetext{
${ }^{12}$ Abul Fada' Isma'il Bin Katsir Bin Katsir, tafsir Ibnu Katsir, (tanpa Kota, Ummil Kitab, tt), hal 1979

${ }^{13}$ Ahmad Muhammad Yusuf Ensiklopedi Tematis Ayat Al-qur'an dan Hadits, 2009(Jakarta, Widya cahaya), Jilid 5 hal 419
} 


\section{Model Pendidikan Multikultural}

pangkat-pangkat kalian dan tidak pula kepada nasab-nasabmu dan tidak pula pada tubuhmu, dan tidak pula pada hartamu, akan tetapi memandang pada hatimu. Maka barang siapa mempunyai hati yang shaleh, maka Allah belas kasih kepadanya. Kalian tak lain adalah anak cucu Adam. Dan yang paling dicintai Allah hanyalah yang paling bertaqwa diantara kalian,”. Jadi jika kalian hendak berbangga maka banggakanlah taqwamu, artinya barang siapa yang ingin memperoleh derajat-derajat tinggi hendaklah ia bertaqwa. Sesungguhnya Allah maha tahu tentang kamu dan amal perbuatanmu, juga maha waspada tentang hatimu, maka jadikanlah taqwa sebagai bekalmu untuk akhiratmu. ${ }^{14}$

Selanjutnya nilai kedamaian dalam Islam sejalan dengan doktrin assalam. Sebagaimana yang termaktub dalam kitab suci al-qur'an, diantara Ayat yg mengandung nilai-nilai kedamaian terdapat dalam QS. An nahl:125 dan QS. Fussilat :34 yang berbunyi;

Qs. An-Nahl:125

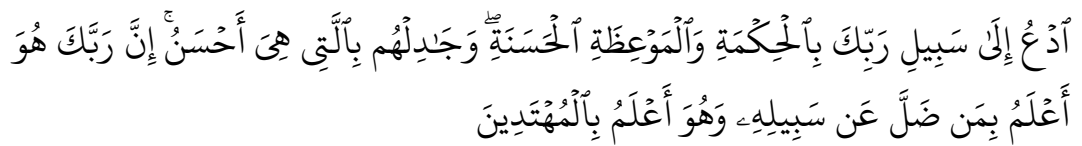

"Serulah (manusia) kepada jalan Tuhan-mu dengan hikmah dan pelajaran yang baik dan bantahlah mereka dengan cara yang baik. Sesungguhnya Tuhanmu dialah yang lebih mengetahui tentang siapa yang tersesat dari jalan-Nya dan dialah yang lebih mengetahui orangorang yang mendapat petunjuk"

Qs. Fussilat 34

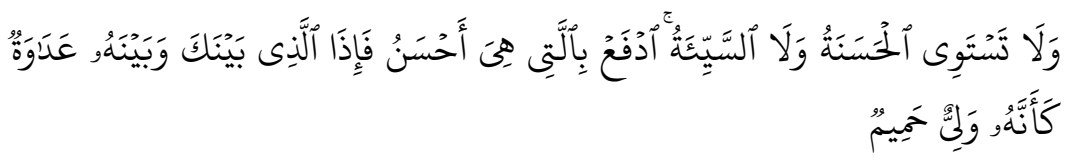

"Dan tidaklah sama perbuatan yang baik dan yang jahat. Tolaklah (kejahatan itu) dengan cara yang lebih baik, maka tiba-tiba antara kamu dan dia ada permusuhan jadikan seolah-olah ia adalah teman yang sangat setia".(Qs: Fushilat : 34).

\footnotetext{
${ }^{14}$ Ahmad Mustofa Al-Maraghi Terjemah Tafsir Al-Maraghi, (Semarang, CV. Toha Putra, 1993). Hal 235-238
} 
Ayat tersebut merekomendasikan agar visi Islam tentang hidup harmonis dan damai dapat terwujud dalam masyarakat yang beragam. Selanjutnya, mengembangkan sikap mengakui, menerima, dan menghargai keragaman. Dalam Islam gejala keragaman harus dterima, diakui dan dihargai, hal tersebut senada dengan konsep al-taadudiyat (pluralisme) dan al-tanawwu' (kergaman). Sebagaimana dalam surat Al-Rum ayat 22. Hud 118-119. Dan Al-maidah ayat 48.

Qs. Ar-Rum 22

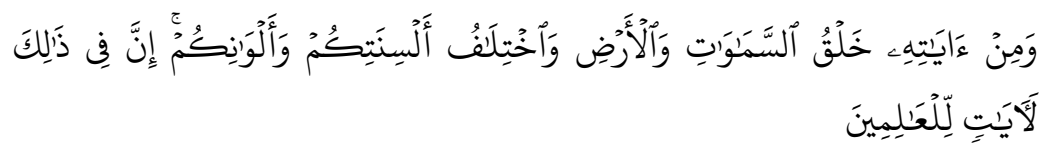

"Dan di antara tanda-tanda kekuasaan-Nya ialah menciptakan langit dan bumi dan berlain-lainan bahasamu dan warna kulitmu. Sesungguhnya pada yang demikian itu benar-benar terdapat tandatanda bagi orang-orang yang mengetahui".

Menurut Ibnu Katsir, ayat ini mengandung arti di antara tanda-tanda kekuasaan-Nya adalah penciptaan langit dan bumi. Dalam arti penciptaan langit dengan ketinggiannya, keluasan hamparan atapnya, kecemerlangan bintang-bintangnya yang tetap dan yang beredar. Serta penciptaan bumi dengan kerendahan dan ketebalannya serta beberapa kandungannya seperti bentuk gunung, oase, laut, padang pasir, hewan, dan pepohonan.Tandatanda kekuasaan Allah yang berikutnya adalah perbedaan bahasa-bahasa yang ada. Ada yang berbahasa Arab, Tartar, Romawi, Perancis, Barbar, Habsyi, Hindi, 'Ajam, Armenia, Kurdi, dan masih banyak lagi. ${ }^{15}$ Keseluruhan dari keragaman bahasa tersebut tidak ada yang mengajarkannya kecuali Allah.Tanda-tanda selanjutnya adalah keragaman warna kulit manusia. Seluruh penduduk Bumi, sejak diciptakannya Adam sampai hari akhir, semuanya memiliki dua mata, dua alis, satu hidung, dua

\footnotetext{
${ }^{15}$ Ibnu Katsir, Tafsir Ibnu Katsir (Jilid 7). Hlm 168.
} 


\section{Model Pendidikan Multikultural}

buah pelipis, satu mulut, dan dua pipi. Meskipun demikian, antara satu dengan yang lainnya tidak memiliki kesamaan. Bahkan dibedakan satu sama lain antara jalannya, sikapnya atau pembicaraannya. Baik nyata ataupun tersembunyi yang hanya dapat terlihat jika melalui perenungan. Seandainya seluruh manusia memiliki kesamaan dalam ketampanan atau kejelekan, niscaya dibutuhkan orang yang membedakan setiap salah satu di antara mereka dengan yang lainnya. ${ }^{16}$

Menurut Imam Al-Qurthubi, hal ini jelas terjadi bukan karena air mani maupun perbuatan dari kedua orang tua. Pasti terdapat pelaku atas semua ini, dan dapat dipastikan bahwa pelakunya adalah Allah S.W.T. Hal ini merupakan dalil yang menunjukkan adanya Tuhan Yang Maha Mengatur dan Maha Menciptakan. ${ }^{17}$ Sedangkan dalam Tafsir fi Zhilalil-Qur'an jilid 9, Sayyid Quthb menerangkan bahwa penciptaan manusia dengan berbagai macam bahasa dan warna kulit, memiliki korelasi dengan penciptaan langit dan bumi yang mengagumkan ini. Adanya perbedaan hawa udara di permukaan bumi dan perbedaan lingkungan yang terjadi karena tabiat kedudukan bumi secara astronomis, mempunyai implikasi terhadap perbedaan bahasa dan warna kulit. ${ }^{18}$

Dari ketiga penafsiran yang telah disampaikan di atas, dapat kita ambil pengetahuan secara umum bahwasanya keteraturan, keselarasan, dan keserasian dalam penciptaan langit dan bumi merupakan tanda-tanda Keagungan Allah S.W.T. Munculnya ilmu pengetahuan merupakan pembuktian adanya Sang Pencipta dan bukan sebaliknya. Adanya keragaman warna kulit dan dialektika merupakan realitas sosial yang tidak bisa dihindarkan. Bahkan Nabi S.A.W juga bersabda: "Al-Qur'an diturunkan dalam tujuh bahasa” (HR Muslim, At-Tirmidzi, dan Ahmad dengan riwayat yang berbeda-beda tetapi dengan makna yang sama).Berdasarkan hadis di atas kita dapat menyimpulkan bahwasanya Al-

\footnotetext{
${ }^{16}$ Ibid,.

${ }^{17}$ Syaikh Imam Al-Qurthubi. Tafsir Al-Qurthubi (Jilid 14). Hlm 42.

${ }^{18}$ Sayyid Quthb. Tafsir fi Zhilalil-Qur'an (Jilid 9). Hlm 139
} 
Qur'an sendiri demikian menghargai bahasa dan keragamannya bahkan mengakui penggunaan bahasa lisan yang beragam. ${ }^{19}$

\section{Dimensi Pendidikan Multikultural}

Banks mengidentifikasi ada lima hal (dimensi) yang saling berkaitan dalam pendidikan multikultural yang diperkirakan dapat membantu guru dalam mengimplementasikan beberapa program yang mampu merespon terhadap perbedaan peserta didik (siswa), yaitu:

\section{a. Content integration (integrasi isi/materi)}

Upaya untuk mengintegrasikan berbagai budaya dan kelompok untuk mengilustrasikan konsep dasar, generalisasi dan teori dalam mata pelajaran/disiplin ilmu. Dalam hal ini guru dapat menggunakan contoh, data dan informasi lain dari berbagai budaya.

b. Knowledge construction proces (kontruksi ilmu pengetahuan)

Membawa peserta didik untuk memahami implikasi budaya ke dalam sebuah mata pelajaran, dalam hal ini guru dapat membantu siswa "memahami bagaimana pengetahuan diciptakan dan bagaimana hal itu dipengaruhi oleh kedudukan ras, etnis, dan kelas sosial individu dan kelompok."

\section{c. Prejudice reduction (pengurangan prasangka)}

Pengurangan prasangka merupakan sasaran penting pendidikan multikultural. Pengurangan prasangka meliputi pengembangan hubungan positif dikalangan siswa dari latar belakang etnis yang berbeda, maupun pengembangan sikap yang lebih demokratis dan toleransi terhadap orang lain.

d. Equitable pedagogy (pendidikan yang sama/adil atau kesetaraan dalam pendidikan)

Merujuk pada penggunaan teknik pengajaran yang mempermudah pemngajaran kepada siswa dari kelompok etnis dan kelas sosial yang berbeda. Sehingga pendidikan multikultural harus diselenggarakan dengan menyesuaikan metode pembelajaran dengan cara belajar peserta didik, hal

\footnotetext{
${ }^{19}$ M. Quraish Shihab. Wawasan Al-Qur'an. Hlm 340.
} 


\section{Model Pendidikan Multikultural}

ini dilakukan dalam rangka memfasilitasi prestasi akademik siswa yang beragam mulai dari ras, budaya maupun social. Sehingga pedagogi kesetaraan ada ketika guru mengubah pengajaran mereka ke cara yang akan memfasilitasi prestasi akademis dari siswa dari berbagai kelompok ras, budaya, dan kelas sosial. Termasuk dalam pedagogi ini adalah penggunaan beragam gaya mengajar yang konsisten dengan banyaknya gaya belajar di dalam berbagai kelompok budaya dan ras.

e. Empowering school culture and social cultur (pemberdayaan budaya sekolah dan struktul sosial)

Budaya sekolah yang memberdayakan adalah budaya yang membuat organisasi dan praktek sekolah bersifat kondusif bagi pertumbuhan akademis dan emosi semua siswa. ${ }^{20}$ Untuk itu, para guru yang memberikan pendidikan multibudaya harus memiliki keyakinan bahwa; perbedaan budaya memiliki kekuatan dan nilai, sekolah harus menjadi teladan untuk ekspresi hak-hak manusia dan penghargaan untuk perbedaan budaya dan kelompok, keadilan dan kesetaraan sosial harus menjadi kepentingan utama dalam kurikulum, sekolah dapat menyediakan pengetahuan, keterampilan, dan karakter ( yaitu nilai, sikap, dan komitmen ) untuk membantu siswa dari berbagai latar belakang, sekolah bersama keluarga dan komunitas dapat menciptakan lingkungan yang mendukung multibudaya.

Berdasarkan dimensi-dimensi tersebut, maka pendidikan multikultural yang di terapkan di sekolah atau madrasah harus memuat ke lima hal tersebut; yaitu dengan mengintenalisasikan muatan materi-materi multikulturan, pertimbangan penggunaan metode pembelajara yang sesuai samapai pada pembiasaan nilai-nilai pendiidkan multikultural dalam kultur sekolah atau madrasah, supaya tujuan pendidikan multikultural dapat tercapai dengan baik.

${ }^{20}$ Robert E Slavin, (2009) Educational Phicology: Theory and Practice, 8th, edition. New Jersey: Personal Education. 


\section{Model-model Pendidikan Multikultural}

Kata model dalam wikipedia diartikan sebagai rencana, representasi, atau deskripsi yang menjelaskan suatu objek, sistem, atau konsep, yang seringkali berupa penyederhanaan atau idealisasi. Bentuknya dapat berupa model fisik (maket, bentuk prototipe), model citra (gambar rancangan, citra komputer), atau rumusan matematis. ${ }^{21}$ Dalam kamus besar bahasa indonesia model berarti pola (contoh, acuan, ragam, dan sebagainya) dari sesuatu yang akan dibuat atau dihasilkan. ${ }^{22}$ Sedangkan pendidikan multikultural sebagaimana yang dijelaskan pada pembehasan sebelumnya adalah merupakan proses penanaman cara hidup menghormati, tulus dan toleran terhadap keragaman budaya yang hidup di tengah-tengah masyarakat plural. Baik itu melalui pendidikan formal (sekolah), non formal (luar sekolah) maupun informal (keluarga). Digagasnya wacana multikultul dalam bidang pendidikan sebagai upaya untuk menumbuhkan kesadaran akan cara hidup demokratis, yang intinya adalah penanaman moral. Melalui pendidikan multikultural, sikap saling menghargai (mutual respect), saling pengertian (mutual understanding), dan saling percaya (mutual trust) dalam menyikapi berbagai perbedaan akan terbangun dan berkembang dengan baik. Tentang cara hidup demokratis al-Murshiy menyebutkan bahwa pendidikan dalam masyarakat yang demokratis bertujuan untuk merealisasikan garis-garis, prinsip dan pemikiran yang termuat dalam ideologi demokratis kepada masyarakat melalui bimbingan dan arahan terhadap individu, dengan cara menyediakan pendidikan dan pengajaran yang benar. ${ }^{23}$

Dari pengertian tersebut sehingga yang dimaksud dengan model pendidikan multikultural adalan suatu konsep penyelengaraan pendidikan multikural yang dijadikan sebagai acuan dalam pelaksanaan pendidikan multikultural.

\footnotetext{
${ }^{21}$ Wikipedia bahasa indonesia online

${ }^{22} \mathrm{KBBI}$

${ }^{23}$ Muni>r al-Murshiy, Sarhan, Fi Ijtima> al-Tarbi $>y a h$ (Mesir: Maktabah al-Anglo alMisriyyah, 1978), 256.
} 


\section{Model Pendidikan Multikultural}

\section{E. Macam-macam Model Pendidikan Multikultural di Sekolah atau Madrasah}

Model pendidikan multikultural di Indonesia, juga di Negara-negara lain, menunjukkan keragaman tujuan yang menerapkan strategi dan sarana yang dipakai untuk mencapainya. Sejumlah kritikus melihat, bahwa revisi kurikulum sekolah yang dilakukan dalam proses pendidikan multicultural di Inggris dan beberapa tempat di Australia dan Kanada, terbatas pada keragaman budaya yang ada; jadi, terbatas pada dimensi kognitif. Penambahan informasi tentang keragaman budaya merupakan model pendidikan multicultural yang mencakup revisi atau materi pembelajaran, termasuk revisi buku-buku teks. Terlepas dari kritik atas penerapannya di beberapa tempat, revisi pembelajaran seperti yang terjadi di Amerika Serikat merupakan strategi yang dianggap paling penting dalam reformasi pendidikan dan kurikulum. Penulisan kembali sejarah Amerika dari perspektif yang lebih beragam merupakan suatu agenda pendidikan yang diperjuangkan intelektual, aktivis dan praktisii pendidikan .

Di Jepang, aktivis kemanusiaan melakukan advokasi serius untuk merevisi buku sejarah, terutama yang menyangkut peran Jepang pada Perang Dunia II di Asia. Walaupun belum diterima, usaha ini sudah mulai membuka mata sebagai masyarakat akan pentingnya perspektif baru tentang perang, agar tragedy kemanusiaan tidak terulang kembali. Sementara, di Indonesia masih diperlukan usaha yang panjang dalam merevisi buku-buku teks agar mengakomodasi kontribusi dalam pertisipasi yang lebih inklusif bagi warga dari berbagai latar belakang suku, agama, budaya dan etnis. Di Indonesia juga memerlukan materi pembelajaran yang bisa mengatasi "dendam sejarah" di berbagai wilayah.

Model lainnya, pendidikan multicultural tidak sekedar merevisi materi pembelajaraan, tetapi juga melakukan reformasi dalam system pembelajaran itu sendiri. Affirmative Action dalam seleksi siswa sampai rekrutmen tenaga pengajar di Amerika adalah salah satu strategi untuk membuat perbaikan ketimpang struktural terhadap kelompok minoritas. 
Contoh yang lain adalah model "sekolah pembauran" Iskandar Muda di Medan yang memfasilitasi interaksi siswa dari berbagai latar belakang budaya dan menyusun program anak asuh lintas kelompok. Di Amerika Serikat, bersamaan dengan masuknya wacana tentang multikulturalisme, dilakukan berbagai lokakarya di sekolah-sekolah maupun di masyarakat luas untuk meningkatkan kepekaan social ( sense of crisis ), toleransi dan mengurangi prasangka antarkelompok

Untuk mewujudkan model-model tersebut, pendidikan multicultural di Indonesia perlu memakai kombinasi model yang ada, agar, seperti yang diajukan Gorski, pendidikan multicultural dapat mencakup tiga jenis transformasi yaitu; 1 ) transformasi diri; 2 ) transformasi sekolah dan proses belajar mengajar, dan 3 ) transformasi masyarakat.

Lebih lanjut, model penyelenggaraan pendidikan multikultur di sekolah dapat dilakukan dengan cara terintegrasi dalam mata pelajaran pada kurikulum tingkat satuan pendidikan. Oleh karena itu, pembelajaran pendidikan multikultur ini diharapkan tidak merubah struktur kurikulum dan tidak menambah alokasi waktu. Penerapan atau pengintegrasian pendidikan multikultur secara jelas terlihat dalam silabus dan RPP. Melalui cara itu, maka akan terimplementasikan dalam kegiatan pembelajaran baik di kelas maupun di luar kelas secara kontekstual. Selain itu, pendidikan multikultur juga bukan Mata Pelajaran terpisah sehingga harus terintegrasi dan bukan merupakan pengetahuan yang bersifat kognitif sehingga materi seyogyanya dikemas dalam bentuk afektif dan kinerja siswa serta pendekatan materinya dapat bersifat tematis. Yang perlu diperhatikan dalam hal ini adalah upaya menerapkan atau mengintegrasikan muatan nilai-nilai yang terkandung dalam pendidikan multikultur kedalam Mata Pelajaran melalui kegiatan-kegiatan sehingga dapat diterapkan dan tercermin dalam kehidupan peserta didik. Selain itu, penerapan atau pengintegrasian pendidikan multikultur harus dilakukan dan terlihat dalam 


\section{Model Pendidikan Multikultural}

aktivitas seluruh warga sekolah maupun dalam manajemen sekolah secara umum. $^{24}$

\section{Daftar Pustaka}

Abul Fada' Isma'il Bin Katsir Bin Katsir, tt,tafsir Ibnu Katsir,tanpa Kota, Ummil Kitab

Ahmad Muhammad Yusuf, 2009, Ensiklopedi Tematis Ayat Al-qur'an dan Hadit,s Jakarta, Widya cahaya ,Jilid5

Ahmad Mustofa Al-Maraghi, 1993, Terjemah Tafsir Al-Maraghi, Semarang: CV. Toha Putra

Banks, james and Cherry McGee Banks (eds). (2001). Multicultural Education Issues and Perspectives. New York: John Wiley and Sons.

Bukhari Umar, 2010, Ilmu Pendidikan Islam, Jakarta: Amzah

H.A.R. Tilaar, 2002, Perubahan Sosial dan Pendidikan: Pengantar Pedagogik Transformatif untuk Indonesia, Jakarta: Grasindo

M. Ainul Yaqin, 2005, Pendidikan Multikultural: Cross-Cultural Understanding untuk Demokrasi dan Keadilan, Yogyakarta:Pilar Media

M. Quraish Shihab. Wawasan Al-Qur'an

Masgnud, 2010, Pendidikan Multikultural: Pemikiran dan Upaya Implementasinya, Yogyakarta: Idea Press

Nimrod aloni, 1999, enciclopedia of humanistic educational. New york: oxford university press

Robert E Slavin, (2009) Educational Phicology: Theory and Practice, 8th, edition. New Jersey: Personal Education.

Sarhan Munir al-Murshiy, 1978, Fi Ijtima`al-Tarbiyah, Mesir: Maktabah al-Anglo al-Misriyyah

\footnotetext{
${ }^{24}$ Puskur Depdiknas tahun 2007
} 


\section{Junaidi}

Sayyid Quthb. Tafsir fi Zhilalil-Qur'an (Jilid 9)

Skeel, Dorothy J. (1995). Elementary social studies : Challenges for tomorrow's world. Harcourt Brace College Publishers.

Skeel, Dorothy J. (1995). Elementary social studies : Challenges for tomorrow's world. Harcourt Brace College Publishers.

Syaikh Imam Al-Qurthubi. Tafsir Al-Qurthubi (Jilid 14). 